\title{
The comparison of the 1972 Hodkinson's Abbreviated Mental Test Score (AMTS) and its variants in screening for cognitive impairment
}

\author{
Karolina Piotrowicz ${ }^{1}$ Wojciech Romanik ${ }^{2}$ - Anna Skalska ${ }^{1}$ Barbara Gryglewska ${ }^{1} \cdot K$ atarzyna Szczerbińska ${ }^{1,3}$. \\ Jarosław Derejczyk ${ }^{4}$. Roger M. Krzyżewski ${ }^{5}$ · Tomasz Grodzicki ${ }^{1}$. Jerzy Gąsowski ${ }^{1}$ (1)
}

Received: 18 April 2018 / Accepted: 13 July 2018 / Published online: 30 July 2018

(c) The Author(s) 2018

\begin{abstract}
Background Since its introduction by Hodkinson in 1972, Abbreviated Mental Test Score (AMTS) and its English and other language versions have been widely used in research and clinical practice alike. However, whether the various versions of AMTS yield equivalent information has never been tested.

Methods We performed cross-sectional assessment of inpatients aged 65+ years with seven AMTS versions and the MiniMental State Examination (MMSE) after correction for age and education (MMSEc). We used the MMSEc cut-off score of $<24$ as comparator and fitted linear regression models from which we obtained the receiver operating characteristics, and further compared the $c$-statistics obtained for each version of AMTS. We used Spearman's correlation to check the relation between different AMTS versions.

Results The mean (SD) age of 72 (52.8\% women) patients was 76.2 (7.6) years. The average time spent on education was 11.3 (3.5) years. The AMTS score across versions varied between 7.4 (2.0) and 8.2 (1.7). The MMSE averaged 24.1 (4.6) and the MMSEc averaged 25.2 (4.1). We found that the $c$-statistic across AMTS versions with dichotomised MMSEc as comparator ranged from 0.83 to 0.85 and did not significantly differ from the $c$-statistic of 0.87 for original AMTS (all $p>0.16$ ). We found AMTS versions to be significantly correlated (all $r$ between 0.83 and 0.99 , all $p<0.0001$ ).

Conclusions We found AMTS to be a reliable and useful tool in the screening for possible cognitive impairment. This seems to be true irrespective of whether we use the original test or any of its studied modifications.
\end{abstract}

Keywords AMTS $\cdot$ MMSE $\cdot$ Cognitive impairment $\cdot$ Validation $\cdot$ Mental test

Jerzy Gąsowski

jerzy.gasowski@uj.edu.pl

1 Department of Internal Medicine and Gerontology, Faculty of Medicine, Jagiellonian University Medical College, 10, Śniadeckich St., 31-351 Kraków, Poland

2 II Department of Anesthesiology and Intensive Care, Central Teaching Hospital, Medical University of Warsaw, Warsaw, Poland

3 Faculty of Medicine, Jagiellonian University Medical College, Kraków, Poland

4 John Paul II Geriatric Hospital, Katowice, Poland

5 Department of Neursurgery and Neurotraumatology, Faculty of Medicine, Jagiellonian University Medical College, Kraków, Poland

\section{Background}

The Abbreviated Mental Test Score (AMTS) was first introduced in 1972 by Hodkinson for the assessment of mental impairment in old age [1]. AMTS is a 10-item screening questionnaire that included in the original version questions about: subject's age, date of birth, the current time and year, the name of hospital, the name of the present British monarch, the year of the beginning of the First World War; and a recall of a previously given address, counting backwards by 1 , from 20 to 1 , and recognition of two persons (e.g., doctor, nurse, etc.) [2].

Based on the search of literature, we found several English language modifications of AMTS [3-6] (summarized in Table 1). We also found a Polish version of AMTS [7, 8] which has been widely used both in clinical practice [8] and research [9] (Table 1). 


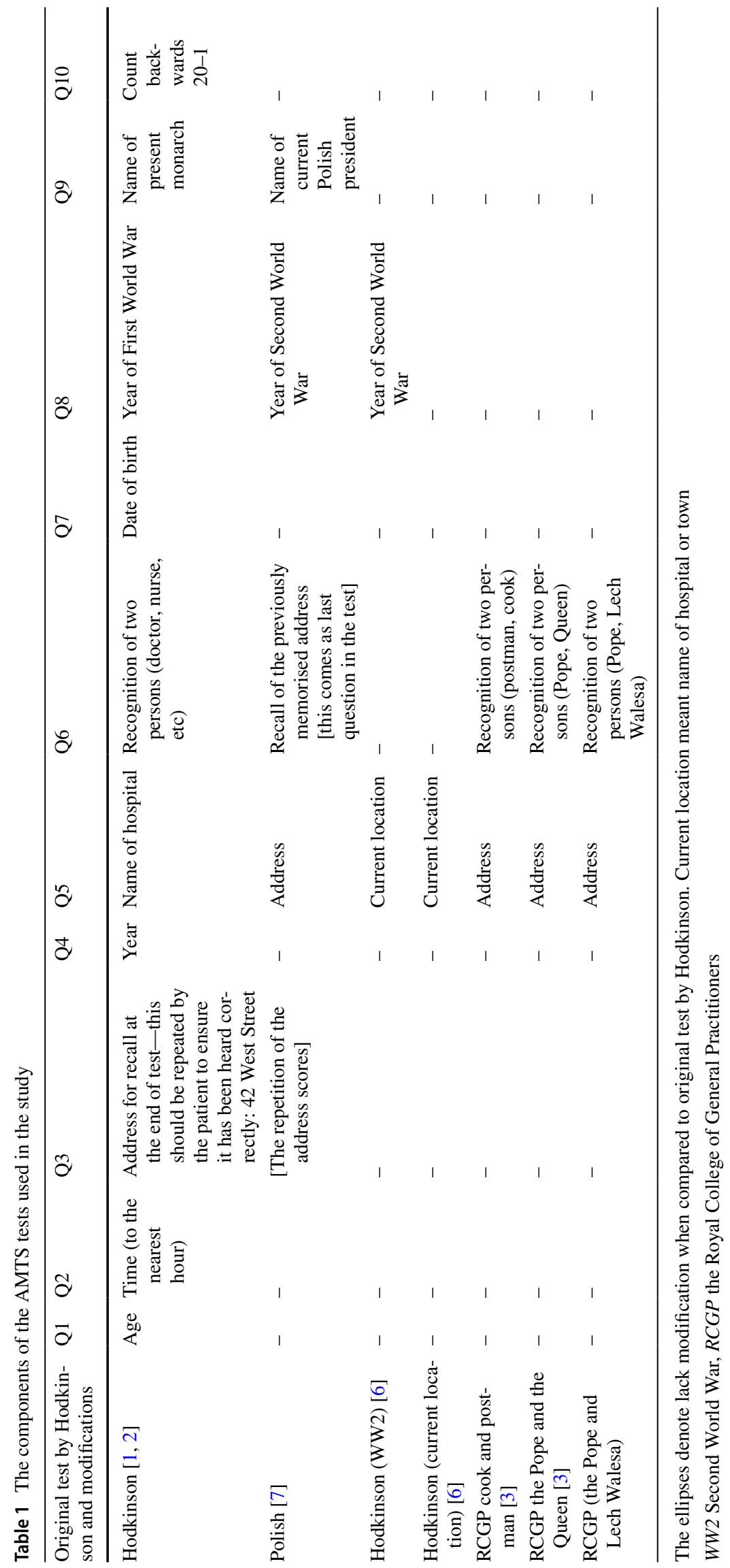


Several papers described validations of some of national versions of AMTS [10-15], or the validity of the original version as published by Hodkinson in 1972 in detecting persons with definite dementia, according to the clinical criteria prevailing during the execution of particular study [16-19], or suspected dementia (based on the MMSE score) [17, 20-22]. However, to the best of our knowledge the widely circulated versions of AMTS, including the Polish modification, have never been compared between one another in terms of their value in detecting suspected cognitive impairment.

\section{Methods}

The aim of the study was to compare the basic diagnostic properties of the Polish translation [7], the English versions published in the Occasional Paper by the Royal College of General Practitioners (RCGP) [3, 4], and the original questionnaire of the Abbreviated Mental Test Score [1, 2]. We employed the Mini-Mental State Examination (MMSE) after correction for age and years of education (MMSEc), as a reference test for suspicion of cognitive impairment, with the MMSEc cut-off score of 24 points (23 or below) [23]. To adjust the results for age and education we used the correction as proposed by Mungas et al. [24]. The threshold score for the cognitive impairment in AMTS was 7 points (6 or below). The comparison of the questionnaires of the original, the Polish version and the English language derivatives of the original AMTS is presented in Table 1. When testing the ability to recognise persons, in the RCGP version of AMTS we used the pictures of a postman and a cook, and the Pope John Paul II and the Queen Elizabeth II. Additionally, we decided to adapt the RCGP version for the Polish clinical environment, and proposed to use a picture of Lech Wałęsa, the first democratically elected president of Poland since the fall of the East Bloc, instead of a picture of the Queen. The study was performed with the approval of the Ethics Committee of the Jagiellonian University, Kraków, Poland (No.: 122.6120.191.2016), and all subjects gave their informed consent to take part in it. All versions of AMTS were translated and back-translated, as applicable, between the English and the Polish by separate members of the research team (KP, JG). We used the validated Polish version of the MMSE [25]. The eligible subjects had to be aged 65 years or more, and they had to be free from an acute disease. The included patients were the inpatients of Dept. of Internal Medicine and Geriatrics, University Hospital, Kraków, Poland or the patients under assessment for planned surgical procedure at the Central Teaching Hospital, Medical University of Warsaw, Warsaw, Poland. The acutely admitted patients were assessed after stabilization of their medical condition.
The data management and analysis were performed with SAS 9.2 (SAS Institute Inc. Cary, NC, USA). Means were compared with Student's $t$ test, proportions with Chi-square test. We employed Spearman's correlation to check for the associations between the respective AMTS versions and the original AMTS as published by Hodkinson in 1972. Based on the logistic regression models with the aforementioned classification based on MMSEc as dependent variable, we assessed the receiver operating characteristics (ROC) for seven versions of AMTS (Table 1). We used the $c$-statistics as estimates of area under the curve (AUC). We compared the AUC for the original AMTS and the AUC for the Polish version of AMTS with the AUC of every other AMTS studied. The comparisons were based on Wald's standard errors and $95 \%$ confidence intervals. All significance levels were two-tailed with $p<0.05$ indicating statistical significance.

\section{Results}

We collected data of 72 consecutive patients ( $52.8 \%$ women) aged 65 years and older with mean (SD) age of 76.2 (7.6) years, and 11.3 (3.5) years of formal education. The MMSE averaged 24.1 (4.6) and the MMSEc averaged 25.2 (4.1). Based on the unadjusted MMSE results, $38.7 \%$ of the subjects had the suspicion of cognitive impairment. After the correction for age and years of education [24] the percentage of subjects with the MMSE $<24$ was $26.0 \%$. The AMTS score across versions varied between 7.4 (2.0) and 8.2 (1.7). Based on the AMTS, the suspicion of cognitive impairment ranged from 12.3 to $21.9 \%$. The inter-version AMTS correlations ranged from 0.83 to 0.99 (all $p<0.0001$ ). The concordances (AUC) between studied AMTS versions and the classification of patients based on MMSEc ranged from 0.83 to 0.87 and did not significantly differ (all $p>0.10$, Table 2 ).

\section{Discussion}

In this cross-sectional study of 72 older subjects, we found that AMTS and its derivative versions had good ( $c$-statistic from 0.83 to 0.87 ) concordance with MMSE after correction according to Mungas et al. [24] in determining a suspicion of cognitive impairment. This does not significantly differ across various English language versions of AMTS currently in use, and the Polish modification of the test. This is reflected by a significant correlation between scores obtained from different versions of AMTS.

The practical universal use of AMTS poses several problems. First, changes at the societal level, education, and the sheer weight of more recent historical events that draw attention of the societies and the individuals alike may raise suspicion that questions pertaining to such entities as the 
Table 2 The AUC statistics based on the ROC analysis between the MMSEc-based suspicion of cognitive impairment (corrected for age and years of education) and the tested versions of the AMTS

\begin{tabular}{lllllll}
\hline ROC model & $\begin{array}{l}\text { Mean (SD) } \\
\text { AMTS score }\end{array}$ & Area & SE & 95\% Wald CI & $\begin{array}{l}p \text { value vs. } \\
\text { Hodkinson }\end{array}$ & $\begin{array}{l}p \text { value } \\
\text { vs. Pol- } \\
\text { ish }\end{array}$ \\
\hline Hodkinson [1,2] & $7.4(2.2)$ & 0.87 & 0.04 & $0.79-0.95$ & - & 0.44 \\
Polish [7] & $8.2(1.7)$ & 0.85 & 0.05 & $0.75-0.95$ & 0.44 & - \\
Hodkinson (WW2) [6] & $8.0(1.8)$ & 0.83 & 0.05 & $0.73-0.93$ & 0.18 & 0.10 \\
Hodkinson (current location) [6] & $7.7(1.8)$ & 0.84 & 0.05 & $0.74-0.94$ & 0.20 & 0.78 \\
RCGP cook and postman [3] & $7.7(1.8)$ & 0.83 & 0.05 & $0.73-0.93$ & 0.16 & 0.59 \\
RCGP the Pope and the Queen [3] & $7.6(1.9)$ & 0.83 & 0.05 & $0.73-0.93$ & 0.17 & 0.50 \\
RCGP (the Pope and Lech Wałęsa) & $8.1(1.8)$ & 0.85 & 0.05 & $0.75-0.95$ & 0.49 & 0.62 \\
\hline
\end{tabular}

$p$ values are for comparisons of respective AUC with the AUC based on the original Hodkinson or the Polish versions, respectively

$A U C$ area under the curve, $R O C$ receiver operating characteristic, $S E$ standard error, $C I$ confidence interval, $W W 2$ Second World War, RCGP the Royal College of General Practitioners beginning of great wars (WW1 vs. WW2) or the rule of British Monarchs, may have different weight currently than they had in the past $[8,14]$. The literature abounds in the modifications of the original inventory [3-6, 8, 14, 15, 26]. In addition, many versions other than those in English language have been created, usually at the time of systemic transformation in Central and Eastern Europe, the Gulf Region, or Far East. Some local versions may not have been based on original work by Hodkinson of 1972, instead, relying on more easily accessible, more recent English language modifications of the original [8].

The English and non-English language versions of AMTS vary on items testing patient's orientation and memory, and visuospatial abilities $[3,4,6,7,11,13-15,19]$.

Several national validations have been published [11, 13-15, 19]. The validation of the Iranian version substitutes the date of WW1 with the Iraqi-Iranian war and the name of the Queen with the name of the then current Iranian leader [14]. In the validation study conducted in Hong Kong, the authors replaced the date of WW1 with the date of midAutumn festival and the name of the Queen with the name of current Governor of the Chinese leader [15], an Italian validation substituted the name of the Queen with the name of the Italian president [19]. We found that similar cultural and historical substitutions made to the original test across the modified AMTS versions we studied did not markedly interfere with the informative value of the tests (Table 2). In this respect, our results lend formal support to the comparisons of the AMTS value in detecting cognitive impairment as published in review papers [17].

Our study should be considered in the context of its possible limitations. First, the patients included were not randomly drawn, instead they were consecutive inpatients drawn from two centers in Poland and did not include any persons for whom English would have been a mother tongue. Thus, the tests were administered in Polish. However, the simple and unequivocal nature of the questions, confirmed in the translation/backtranslation process, left little room for bias. Another limitation may be attributed to the fact the variants of the test were administered as added on top of the core of the inventory (see Table 1). However, this was done to exclude interpretational problems which might arise due to a learning phenomenon potentially associated with repeated administration of the core inventory [27]. As a standard we used MMSE (validated Polish version purchased by WR and JG, http://www.en.practest.com.pl/node/28991) which only approximates mental function. However, the test has been extensively used for research and clinical purposes worldwide. To minimise the probability of type II error, we performed the sample size assessment which indicated that our study had approximately $80 \%$ power to detect the difference between ROC curves of 0.2 (0.95 vs. 0.75 ) with $5 \%$ significance, with the assumption that under the null hypothesis the ROCs under comparison would equal 0.85 .

In conclusion, in line with some of the previous studies $[10,12,17,22,28,29]$, we found AMTS to be a reliable and useful tool in the screening for possible cognitive impairment with Mungas-adjusted MMSE of $<24$ as comparator. This seems to be true irrespective of whether we use the original test or any of its studied modifications. Despite the fact that the study was performed on Polish population, the implications extend well beyond a single country. Thus far, to the best of our knowledge, no study formally addressed the issue of whether different variants of AMTS currently in use would perform equally against a standard, broadly used measure such as MMSE. We show that indeed they do, and that the ROCs revolve about the value of 0.85. Previously, we showed that subclinical changes in the AMTS correlate with poor compliance with prescribed antihypertensive regimen and worse blood pressure control in a randomly drawn cohort of 1988 community living older hypertensive patients [9]. Our current data give support for the continued use of this important brief assessment tool in daily practice, especially outside of the specialized geriatric setting. 


\section{Key points}

- AMTS is an easy to perform tool for screening assessment of cognition in older subjects.

- Many modifications of the test exist, however whether their screening value is comparable has never been tested.

- We found that irrespective of modifications of questions in AMTS, its screening performance is satisfactory.

- We advocate use of AMTS and its variants in the quick cognitive screening of older patients.

Author contributions JG, KP and WR had the idea of this study and all authors were involved in study design. KP, WR and AS obtained the data. KP, WR and JG extracted the data. JG and KP did the statisti$\mathrm{cal}$ analysis. All authors were involved in data interpretation. JG and KP wrote the 1st draft of the manuscript. JG, KP, RMK prepared the final version. All authors revised the article and gave final approval for submission.

\section{Funding None.}

\section{Compliance with ethical standards}

Conflict of interest The authors report no conflicts of interest.

Ethical approval The study was performed with the approval of the Ethics Committee of the Jagiellonian University, Kraków, Poland (No.: 122.6120.191.2016).

Informed consent All subjects gave their informed consent.

Open Access This article is distributed under the terms of the Creative Commons Attribution 4.0 International License (http://creativeco mmons.org/licenses/by/4.0/), which permits unrestricted use, distribution, and reproduction in any medium, provided you give appropriate credit to the original author(s) and the source, provide a link to the Creative Commons license, and indicate if changes were made.

\section{References}

1. Hodkinson HM (1972) Evaluation of a Mental Test Score For Assessment of Mental Impairment in the Elderly. Age Ageing $1: 35-40$

2. Hodkinson HM (2012) Evaluation of a mental test score for assessment of mental impairment in the elderly. 1972. Age Ageing 41:iii35-iii40

3. (1993) Abbreviated Mental Test Score (AMTS). Occas Pap R Coll Gen Pract 28

4. (2002) Abbreviated Mental Test Score (AMTS). Occas Pap R Coll Gen Pract 48

5. Odor PM, Chis Ster I, Wilkinson I et al (2017) Effect of admission fascia iliaca compartment blocks on post-operative abbreviated mental test scores in elderly fractured neck of femur patients: a retrospective cohort study. BMC Anesthesiol 17:1-8. https://doi. org/10.1186/s12871-016-0297-8

6. (2018) http://www.oxfordmedicaleducation.com/geriatrics/amts/. Accessed 17 Mar 2018
7. Kocemba J, Grodzicki T (2000) Geriatryczne Skale Oceny. Zarys Gerontologii Klinicznej. Medyczne Centrum Kształcenia Podyplomowego Uniwersytetu Jagiellońskiego, Kraków, pp 142-151

8. Romanik W, Łazarewicz M (2017) The Polish version of the Abbreviated Mental Test Score (AMTS) — methodology issues. Psychiatria I Psychologia Kliniczna 17:203-207. https://doi. org/10.15557/PiPK.2017.0024

9. Piotrowicz K, Prejbisz A, Klocek M et al (2016) Subclinical mood and cognition impairments and blood pressure control in a large cohort of elderly hypertensives. J Am Med Dir Assoc 17:864. e17-864.e22. https://doi.org/10.1016/j.jamda.2016.06.021

10. Jitapunkul S, Pillay I, Ebrahim S (1991) The abbreviated mental test: its use and validity. Age Ageing 20:332-336

11. Sarasqueta C, Bergareche A, Arce A et al (2001) The validity of Hodkinson's Abbreviated Mental Test for dementia screening in Guipuzcoa, Spain. Eur J Neurol 8:435-440

12. Rocca WA, Bonaiuto S, Lippi A et al (1992) Validation of the Hodkinson abbreviated mental test as a screening instrument for dementia in an Italian population. Neuroepidemiology 11:288-295

13. Bonaiuto S, Rocca WA, Lippi A et al (1992) Study on the validity of the Hodkinson Abbreviated Mental Test Score (AMTS) in detecting dementia of elderly subjects in appignano (Macerata province), Italy. Arch Gerontol Geriatr 15:75-85

14. Foroughan M, Wahlund LO, Jafari $Z$ et al (2017) Validity and reliability of Abbreviated Mental Test Score (AMTS) among older Iranian. Psychogeriatrics 17:460-465. https://doi.org/10.1111/ psyg. 12276

15. Chu L, Pei C, Ho M et al (1995) Validation of the Abbreviated Mental Test (Hong Kong version) in the elderly medical patient. Hong Kong Med J 1:207-211

16. Flicker L, Logiudice D, Carlin JB et al (1997) The predictive value of dementia screening instruments in clinical populations. Int $\mathbf{J}$ Geriatr Psychiatry 12:203-209

17. Jackson TA, Naqvi SH, Sheehan B (2013) Screening for dementia in general hospital inpatients: a systematic review and metaanalysis of available instruments. Age Ageing 42:689-695. https ://doi.org/10.1093/ageing/aft145

18. Gomez de Caso JA, Rodriguez-Artalejo F, Clavería LE et al (1994) Value of Hodkinson's test for detecting dementia and mild cognitive impairment in epidemiological surveys. Neuroepidemiology 13:64-68

19. Antonelli Incalzi R, Cesari M, Pedone C et al (2003) Construct validity of the abbreviated mental test in older medical inpatients. Dement Geriatr Cogn Disord 15:199-206

20. Mitchell AJ, Malladi S (2010) Screening and case finding tools for the detection of dementia. Part I: evidence-based meta-analysis of multidomain tests. Am J Geriatr Psychiatry 18:759-782

21. MacKenzie DM, Copp P, Shaw RJ (1996) Brief cognitive screening of the elderly: a comparison of the Mini-Mental State Examination (MMSE), Abbreviated Mental Test (AMT) and Mental Status Questionnaire (MSQ). Psychol Med 26:427-430

22. Swain DG, O`Brien AG, Nightingale PG (1999) Cognitive assessment in elderly patients admitted to hospital: the relationship between the Abbreviated Mental Test and the Mini-Mental State Examination. Clin Rehabil 13:503-508. https://doi. org/10.1191/026921599670895633

23. Folstein MF, Folstein SE, McHugh PR (1975) "Mini-mental state". A practical method for grading the cognitive state of patients for the clinician. J Psychiatr Res 12:189-198

24. Mungas D, Marshall SC, Weldon M et al (1996) Age and education correction of Mini-Mental State Examination for English- and Spanish-speaking elderly. Neurology 46:700-706

25. No Title n.d (2018) https://www.practest.com.pl/minimental-krotk a-skala-oceny-stanu-umyslowego-mmse. Accessed 17 Mar 2018 
26. Pinkas J, Gujski M, Humeniuk E et al (2016) State of Health and quality of life of women at advanced age. Med Sci Monit 22:3095-3105. https://doi.org/10.12659/MSM.900572

27. Houx PJ, Shepherd J, Blauw G-J et al (2002) Testing cognitive function in elderly populations: the PROSPER study. PROspective Study of Pravastatin in the Elderly at Risk. J Neurol Neurosurg Psychiatry 73:385-389. https://doi.org/10.1136/jnnp.73.4.385
28. Antonelli Incalzi R, Cesari M, Pedone C et al (2003) Construct validity of the 15 -item geriatric depression scale in older medical inpatients. J Geriatr Psychiatry Neurol 16:23-28

29. Harwood DMJ, Hope T, Jacoby R (1997) Cognitive impairment in medical inpatients. II: screening for dementia-is history better than mental state? Age Ageing 26:37-39 